\title{
O sentido da formação profissional no contexto da aprendizagem
}

\author{
Orlando Júnior Viana Macêdo \\ Maria de Fátima Pereira Alberto \\ Universidade Federal da Paraiba
}

\begin{abstract}
Resumo
Neste artigo, discute-se o sentido da formação para o trabalho. Priorizou-se a metodologia qualitativa mediante entrevistas semiestruturadas. Trabalhou-se com dezesseis sujeitos, de 14 a 18 anos, na cidade de João Pessoa-PB. Os dados foram analisados por meio da técnica de análise temática. As falas denotaram que adolescentes procuram o programa por visualizarem oportunidade de inserção no mercado de trabalho e por auferirem uma renda. A aprendizagem ficou em terceiro plano. Após essa vivência, eles se tornaram mais "disciplinados" e assimilaram "conteúdos teóricos" do curso. Desempenharam também atividades dos setores de administração, apoio e comércio. Percebe-se a construção de uma subjetividade modelada sob a lógica do capital, uma vez que os sujeitos são adestrados ao mundo do trabalho, levando em consideração o que esperam enquanto futuros trabalhadores. Disso sobressaem elementos indicativos de que tal proposta se enquadra numa filosofia da formação profissional que visa adestrar para uma posição no processo de produção.

Palavras-chave: sentido da aprendizagem profissional; disciplinamento; formação profissional; adolescência.
\end{abstract}

\begin{abstract}
The meaning of vocational training in the learning context. This article discusses the meaning of work training. Qualitative methodology was prioritized by using semi-structured interviews. Sixteen individuals were analyzed, aged between 14 to 18 , in the city of João Pessoa-PB. The data were analyzed by means of thematic analysis technique. The lines denoted that adolescents seek the program because they see in it the opportunity of insertion in the labor market, as well as earning an income. Learning came in third level. After that experience they have become more "disciplined" and assimilated "theoretical contents" of the course. Administrative, supportive and commercial sectors activities were also performed. The construction of a subjectivity modeled under the logic of capital is perceived, once the individuals are prepared for the employment world, considering what they expect from themselves as future employees. From this, elements stand out indicating that such proposal fits into a professional training philosophy that aims to tame into a position within the production process.
\end{abstract}

Keywords: meaning of vocational training; discipline; vocational training; adolescence.

$\mathrm{O}$ presente estudo versa sobre uma pesquisa que analisa o sentido atribuído pelos adolescentes aprendizes a um programa de formação profissional. Para isso, faz-se necessário um breve resgate histórico das propostas de formação destinadas a esse segmento social, objetivando mostrar que embora haja, aparentemente, com o Estatuto da Criança e do Adolescente uma mudança na forma do Estado operacionalizar as políticas públicas de formação profissional para jovens, continua havendo reprodução de um imaginário do trabalho como disciplinador. Concepção essa que se faz presente no sentido apresentado pelos jovens participantes da pesquisa acerca da formação profissional.

Com base em um resgate histórico, percebe-se no Brasil certo imaginário que considerava ser papel do Estado e da sociedade intervir, por meio de gestão e tutela dos jovens pobres, de forma a possibilitar o encaminhamento destes para o mundo do trabalho, pois eram considerados potencialmente "perigosos".
Tal imaginário vem possibilitando configuração de políticas e concepções excludentes, exploratórias e disciplinadoras, conforme chamam atenção Pilotti e Rizzini (1995), Marcílio (1999), Martins e Brito (2003), Coimbra e Nascimento (2005), Cruz, Hillesheim e Guareshi (2005), Kuhlmann Jr. (2005), Siqueira e Dell'Aglio (2006) e Frigotto (2008). Essas concepções podem ser visualizadas a partir de uma retrospectiva das políticas sociais voltadas para os jovens.

No Brasil Império, a política conduzida pelo Estado, como assinalam Pilotti e Rizzini (1995), não se dava no sentido de proteção, mas, sim, de encaminhamento ao trabalho, uma vez que esses sujeitos eram considerados "propriedade individual do senhor seu dono, como patrimônio e mão-de-obra" (Pilotti \& Rizzini, 1995, p.224).

Com o aumento, no século XVIII, do número de crianças abandonadas nas ruas, terrenos baldios, portas de igrejas e residências, foram criadas as Rodas de Expostos nas Santas 
Casas de Misericórdia, que consistiam em todo um sistema legal e assistencial das crianças abandonadas até sua maioridade, objetivavam salvar as vidas dos recém-nascidos abandonados para encaminhá-los depois a trabalhos produtivos e forçados, como forma de ressarcirem seus "criadores" ou o Estado pelos gastos feitos com sua criação, como assinalam Cruz, Hillesheim e Guareschi (2005). Validava-se e institucionalizava-se, assim, o enjeitamento da criança desvalorizada (negra, mestiça, ilegítima), ao mesmo tempo em que a incorporava ao trabalho, como "cria" ou como trabalhador não assalariado.

Essa "assistência social” ou "ajuda do Estado" ofertada aos "enjeitados" denota a tônica que se constituiu no imaginário da sociedade brasileira e na legislação "menorista" de caráter corretivo, pois tinha como orientação educar, disciplinar física, moral e civicamente as crianças e os adolescentes oriundos de famílias “desajustadas" ou "órfãs". O propósito era evitar que viessem a se tornar um problema social futuro.

É sob esse prisma, de formação como antídoto à marginalidade, que começa a configurar-se uma preocupação do Estado brasileiro com a formação profissional. Segundo Pilotti e Rizzini (1995), os primeiros sinais de preocupação com a formação já se faziam presentes nos Asilos da Infância dos Menores Desvalidos, de 1854, cuja finalidade consistia em torná-los úteis à sociedade e ao Governo. Vale salientar que os ofícios aprendidos por essas crianças por meio desse processo de formação, conforme assinalam Cristo e Rangel (2007), não traziam nenhuma possibilidade de inserção em postos de trabalhos bem remunerados, não possibilitavam ascensão social, mantendo-se, assim, o perverso ciclo vicioso da pobreza. Configuravam também a intenção de apenas contê-los, através do adestramento por intermédio do trabalho, não se diferenciando em muito do propósito do Sistema de Roda das Santas Casas de Misericórdia.

Poucos anos depois, em 1909, foram criadas as Escolas de Aprendizes Artífices, cuja filosofia não se distinguia das demais. Tal proposta destinava-se tanto aos denominados "menores viciosos", em conflito com a lei, quanto aos que fossem encontrados a sós, em via pública, por falta ou omissão dos pais. Essas crianças eram institucionalizadas e encaminhadas ao trabalho pela própria instituição que as abrigava a troco do seu sustento. Pilotti e Rizzini (1995) chamam a atenção para o fato de essa intervenção do Estado se realizar como forma de categorização e de exclusão, sem modificar a estratégia de manutenção da criança no trabalho.

Alguns acontecimentos, no início do século XX, que se deram tanto no cenário nacional como internacional, acabaram por exercer influência na política brasileira de formação de jovens para o trabalho, que vinha se configurando, sob o prisma do trabalho, como um antídoto à marginalidade.

O primeiro, no âmbito internacional, refere-se ao espaço que o direito do trabalhador ganha nas discussões humanísticas, sendo criada, em 1919, a Organização Internacional do Trabalho - OIT, que, nesse mesmo ano, expediu a Convenção $n^{\circ} 5$, a qual proibia o trabalho de menores de 14 anos em estabelecimentos industriais. No entanto, repercussões mais expressivas nas políticas públicas voltadas para as crianças, adolescentes e jovens, só se fizeram presentes no final do século em questão, por volta dos anos 1980 .

No ano de 1920, foi fundada a Associação Brasileira de Educação - ABE e o Conselho Nacional de Educação em 1927, sendo que, neste ano, foi realizada, também, uma reforma educacional que organizou o ensino profissional.

Em 1927, foi promulgado, sob forma de decreto, o Código de Menores, que incorporava tanto uma visão higienista de proteção do meio e do indivíduo como a visão jurídica repressiva e moralista. De acordo com Pilotti e Rizzini (1995), nesse Código, a orientação prevalecente da política para as crianças e jovens se coloca como um "problema de menor", mostrava dois encaminhamentos, o abrigo e a disciplina, a assistência e a repressão. Havia emergência de novas obrigações do Estado em cuidar da infância pobre com educação, formação profissional, encaminhamento e pessoal competente. Ou seja, uma preocupação com a infância e a juventude, sendo esta norteada, mais uma vez, pelo receio de esses, em um futuro próximo, poderem vir a compor as "classes perigosas", devendo, assim, essas crianças, adolescentes e jovens "em perigo" terem suas virtualidades sob controle permanente.

Dez anos mais tarde, a Constituição Outorgada de 1937 dispôs que era dever do Estado propiciar educação à infância e à juventude pobre. Como fomento à profissionalização dos filhos dos operários, estabeleceu-se a obrigação de as indústrias e os sindicatos econômicos criarem, na esfera de suas especificidades, escolas de aprendizes destinadas especificamente aos filhos de seus operários ou associados. Passa, então, a educação profissional a receber maior colaboração das classes produtoras.

Essa constituição destinou à formação profissional para as classes mais pobres (art. 129), respaldando a dualidade intrínseca à formação social brasileira, ou seja, trabalho manual para uns e trabalho intelectual para outros. Persistia, assim, a tônica discriminatória e disciplinadora.

Esse esforço em definir políticas sistemáticas de intervenção, com o intuito de "conter", bem como de "recuperar" e "reintegrar", manifesta-se também no Serviço de Assistência ao Menor (SAM) de 1942, que viabilizou os reformatórios que abrigavam, sob regime disciplinar, os "menores delinquentes". Segundo Martins e Brito (2003, citado por Cruz, Hillesheim \& Guareschi, 2005), esses reformatórios apresentavam estrutura análoga ao sistema penitenciário. Com o Golpe Militar, o SAM foi extinto. A intervenção pública sobre as crianças e adolescentes passou então a ser instrumentalizada pela Política Nacional de Bem-Estar do Menor (PNBEM), que partia do pressuposto de que o "menor" era um ser "doente" que necessitava de tratamento, oferecido por meio de ação corretiva da FUNABEM, que buscava evitar, assim, que o "menor" incorresse no processo que o levaria à marginalização, o que representava um fator de risco para a ordem e paz social.

De acordo com o Centro Internacional de Investigação e Documentação sobre Formação Profissional (1998), a discussão a respeito da formação e qualificação profissional só veio a se iniciar no Brasil, de maneira mais consistente nos anos 1950, uma vez que a educação pública não tinha capacidade de resposta com a rapidez requerida às necessidades do mercado de trabalho emergentes e específicas de cada setor industrial. Nesse contexto é que, em 1946, surge o Serviço Nacional de Aprendizagem 
Comercial - SENAC, que viria a compor os Serviços Nacionais de Aprendizagem.

Tais iniciativas vieram reforçar a tônica discriminatória e classificadora da Constituição Outorgada de 1937, segmentando a educação brasileira em duas partes. Continuava, assim, o Estado, ao proporcionar oportunidades diferenciadas para os adolescentes e jovens, a depender da classe social a que eles pertenciam, haja vista o fato de haver uma formação geral ou intelectual para os filhos da classe mais abastada, e apenas um ensino primário e profissional para as classes populares.

Vale lembrar que anos mais tarde, com a Constituição de 1967, limitou-se a idade da proibição para o trabalho, que passou a ser de 12 anos, de acordo com o inciso $\mathrm{X}$ do artigo 158. Visava-se, assim, limitar a incorporação de mão de obra ao mercado de trabalho, reforçando a estratégia de exploração da mão de obra de trabalhadores precoces, tanto com o propósito de contê-los, quanto de atender a incipiente e progressiva demanda decorrente da industrialização que vinha ocorrendo no Brasil, mais especificamente da região sudeste.

Percebe-se, dessa forma, que a tônica do caráter disciplinador vinha se fazendo presente ao longo da história das políticas de formação para os adolescentes e jovens no Brasil. Em 1986, configurou-se novamente proposta seguindo essa tônica, já que foi desenvolvido um programa intitulado "Bom Menino", cuja essência era o encaminhamento de crianças e adolescentes das classes populares para o trabalho. Na prática, de acordo com Guareshi (1988), tal programa se justificava como prevenção à marginalidade, assumindo, portanto, um caráter disciplinador.

A Constituição de 1988 modifica essa lógica, pois revolucionou a forma de lidar com os brasileiros em idade infantil ou juvenil, aplicando a doutrina internacional da proteção integral das crianças e adolescentes, por meio de emenda popular subscrita por um milhão e meio de cidadãos que foi assinada pela Assembleia Nacional Constituinte, como assinala Rocha (2007).

Segundo tal autora, o fato mais importante da aprovação da emenda popular foi o artigo 227 da Constituição Federal de 1988 que prevê, como sendo dever da família, da sociedade e do Estado, assegurar à criança e ao adolescente, com absoluta prioridade, o direito à vida, à saúde, à alimentação, à educação, ao lazer, à profissionalização, à cultura, à dignidade, ao respeito, à liberdade e à convivência familiar e comunitária, além de colocá-los a salvo de toda forma de negligência, discriminação, exploração, violência, crueldade e opressão (Brasil, 1988).

Dessa forma, a sociedade passou a ter o dever de zelar e, principalmente, de proteger as crianças e adolescentes, com intuito de prepará-los para que, no futuro, se tornem uma base de sustentação da ordem política e social do país. Configurase, assim, claramente a valorização do trabalho, com vistas à erradicação das desigualdades sociais, colaborando, dessa forma, com a dignidade humana como um princípio fundamental.

As discussões do final dos anos 1980 culminaram com a sanção do Estatuto da Criança e do Adolescente (Brasil, 1990), o qual estabeleceu o caminho para a intervenção popular nas políticas de assistência, traçando as diretrizes da política de atendimento.

A doutrina de proteção integral que orienta o ECA estabelece o aumento da idade de proibição do trabalho da criança ou adolescente. Outras repercussões também se fizeram presentes. No capítulo V, o ECA trata do direito à profissionalização e à proteção no trabalho. No Art. 60 proíbe-se qualquer trabalho a menor de dezesseis anos, salvo na condição de aprendiz, a partir dos quatorze anos de idade. E, no Art. 63, garante-se formação técnico-profissional que respeite o acesso e frequência obrigatória ao ensino regular, em compatibilidade com o desenvolvimento do adolescente e horário especial para o exercício das atividades.

Nesse cenário, a formação profissional começa a configurarse sob uma lógica diferente. Uma vez que a idade permitida para a inserção no mundo de trabalho aumenta, configura-se uma preocupação acerca da condição com a qual está se dando a inserção dos adolescentes no mundo laboral, bem como uma preocupação em relação ao respeito às condições especiais de desenvolvimento da criança e do adolescente, o que pode ser observado a partir de algumas preocupações que se fazem presentes nos marcos legais acerca do trabalho na condição de aprendizagem permitido para sujeitos a partir de 14 anos.

A condição de aprendizagem define-se como aquela em que o adolescente se profissionaliza trabalhando, dentro de um processo educacional previsto na Lei 10.097 (Brasil, 2000). Compreende uma diversidade de cursos, cujo objetivo é propiciar o conhecimento teórico-prático de determinado ofício e cujo exercício exige pré-qualificação. Esse tipo de formação é ministrada por entidades do Serviço Nacional de Aprendizagem, além de Escolas Técnicas e organizações não-governamentais (ONGs).

No caso do presente estudo, trata-se da formação profissional de uma dessas instituições do "Sistema S", realizada na cidade de João Pessoa, no estado da Paraíba, cuja política objetiva preparar os sujeitos para atuarem em atividades que envolvam serviços administrativos. Tal formação apresenta carga horária de $1128 \mathrm{~h}$, sendo $232 \mathrm{~h}$ de conteúdos teóricos e $896 \mathrm{~h}$ de conteúdos práticos. A carga horária diária é de $6 \mathrm{~h}$, distribuídas da seguinte forma: $2 \mathrm{~h}$ no SENAC e 4 h na empresa em que é realizada a parte prática.

Essa política de formação está expressa na Cartilha de Aprendizagem (SENAC, 2004). Tal documento deixa claro o fato de, teoricamente, fazer-se presente uma preocupação com o desenvolvimento físico, psíquico, moral e social dos adolescentes, bem como com a compatibilidade do trabalho com as especificidades dessa fase de desenvolvimento.

Teoricamente, essa nova proposta de formação destoa de todas as outras políticas desenvolvidas para os adolescentes das classes populares, uma vez que, historicamente, sempre se fez presente uma concepção excludente e exploratória, o que despertou interesse por parte dos pesquisadores em investigar o sentido que os adolescentes atribuem a tal proposta de formação para o trabalho. Esse interesse se configurou por meio dos seguintes questionamentos: qual o sentido dessa proposta de formação profissional? O que esses adolescentes, de fato, aprendem? Essa aprendizagem respeita as especificidades e as necessidades biopsicossociais desses sujeitos em processo de desenvolvimento? Ou mais uma vez legitima o trabalho precoce e permite controlar socialmente a pobreza?

Há vários estudos sobre as políticas destinadas às crianças e adolescentes de classes populares, a saber: Guareshi (1988), que analisa a experiência do programa "Bom menino" implementado 
no governo federal, de 1986; Sposito e Corrochano (2005), que investigam os pressupostos orientadores de programas sociais públicos destinados a jovens pobres no Brasil e que envolvem transferência de renda; Gonçalves e Garcia (2007), que discutem o alcance das políticas de atenção à infância e à adolescência, em particular aquelas voltadas para o adolescente em conflito com a lei; Rocha (2007), que aborda o impacto da Lei de Aprendizagem na redução dos atos infracionais cometidos por adolescentes; Trevisan e Bellem (2008), que apreciam, a partir de um resgate histórico, as políticas públicas brasileiras destinadas a crianças e adolescentes; Amparo, Galvão, Cardenas e Koller (2008), que examinam a percepção de jovens em situação de risco psicossocial sobre a rede de apoio social relacionada ao contexto de ensino-aprendizagem; Frigotto (2008), que discute as políticas de formação profissional a partir de uma análise macroestrutural, entre outros.

Apesar dessas várias análises acerca das políticas destinadas aos adolescentes e jovens, poucos estudiosos têm se debruçado sobre a questão da Lei de Aprendizagem, sendo que, nesses estudos, pouco espaço tem sido disponibilizado para esses sujeitos avaliarem tais propostas, o que justifica um estudo acerca do sentido que esses sujeitos atribuem à formação profissional auferida através de um programa de aprendizagem.

\section{Aspectos metodológicos}

Os participantes da pesquisa foram 16 (dezesseis) adolescentes, tanto do sexo masculino quanto do sexo feminino, do Programa de Aprendizagem do SENAC, da cidade de João Pessoa-PB, dos quais 09 (nove) eram participantes, na época das entrevistas, e 07 (sete) eram egressos. Optou-se por se trabalhar tanto com os adolescentes que estavam participando do Programa Adolescente Aprendiz quanto com os que tinham participado de tal programa, porque se tinha como pressuposto que ambos os grupos se diferenciariam em termos de percepção em relação à formação para o trabalho fornecida pelo Programa Adolescente Aprendiz, bem como em termos da inserção no mercado de trabalho possibilitado por este programa e das expectativas em relação ao futuro, aspectos estes que não se confirmaram.

Para identificar o sentido que os adolescentes atribuíam ao programa de formação profissional, procedeu-se a pesquisa por meio de entrevistas individuais, coletivas e análise de documentos. As questões norteadoras das entrevistas contemplavam os seguintes aspectos: idade; sexo; escolaridade; motivação para participar do programa de formação profissional e aprendizado advindo dessa política de formação.

Uma vez autorizada pelo Conselho de Ética, foi agendado um primeiro contato com os responsáveis pelo desenvolvimento do programa de aprendizagem, o que possibilitou que os pesquisadores chegassem aos participantes da pesquisa. Esses, antes de serem entrevistados individualmente, ouviram uma breve explanação dos objetivos da pesquisa e foram informados, também, acerca da garantia do anonimato e da não obrigatoriedade em participarem da pesquisa ou de continuarem até o final dela.

Nas entrevistas coletivas procurou-se explorar os comentários que expressavam posições consensuais, contraditórias ou mesmo singulares, funcionando, assim, como espaço de validação das interpretações e elaborações.

Depois de realizadas todas as entrevistas, elas foram transcritas, sendo esta primeira versão fiel à fala do entrevistado. Em seguida, foi realizada uma leitura flutuante de todo o material e uma tabulação, que consistiu numa agregação das temáticas semelhantes, posteriormente uma codificação, esclarecendo ao analista acerca das características do texto (Bardin, 1995). Desta codificação emergiram as categorias representativas de cada temática, sendo as temáticas e as respectivas categorias: Sentido Atribuído à Inserção no Programa de Aprendizagem - inserção no mercado de trabalho, necessidade financeira e aprendizado; Sentido do Aprendizado - disciplinamento e conteúdo do curso teórico; Sentido da Contribuição da Experiência disciplinamento, vivência de uma experiência, carteira assinada, referência e aprendizado.

\section{Resultados e discussão}

Todos os participantes da pesquisa estudavam em escolas públicas e eram membros da classe popular, já que rendimento mensal familiar, dividido pelo número de componentes da família, foi de R $\$ 200,00$, ou seja, aproximava-se em muito da colocada pelo IBGE como renda a ser considerada abaixo da linha de pobreza ( $1 \frac{1}{2}$ salário mínimo per capita). A escolaridade variava da $8^{\mathrm{a}-\text { série }^{1}}$ do ensino fundamental ao superior incompleto, predominando o $2^{\circ}$ ano do ensino médio.

\section{Sentido atribuido à inserção no programa de apren- dizagem}

Quando questionados acerca do que os motivou a procurarem o programa, as falas revelaram o desejo de inseriremse no mercado formal de trabalho, bem como o interesse em satisfazer necessidades de ordem financeira, ficando em terceiro plano a procura do curso motivada pelo desejo de aprendizado.

A motivação para participar do programa que teve como temática enunciadora a possibilidade de inserção no mercado de trabalho foi a que predominou. Sendo essa possibilidade considerada pelos sujeitos como consequência de o programa oferecer: "carteira assinada", "currículo", "experiência", bem como a "referência conceituada da instituição", o que demonstra que, na percepção dos adolescentes, o que o mercado requer e o programa oferece passa por essas dimensões de uma prática comprovada.

A inserção como objetivo da formação está elencada no próprio discurso oficial. De acordo com o plano de curso do SENAC, um dos objetivos específicos do Programa Jovem Aprendiz consiste em: "propiciar a inserção no mercado de trabalho" (SENAC, 2004, p.15).

Essa busca de espaço no mercado de trabalho é colocada por Cassab (2005) como a necessidade de serem identificados como trabalhadores. Essa autora acrescenta que a adesão à identidade de trabalhador é vista como estratégia de preservação da própria vida e tentativa de autoproteção frente aos riscos a partir da sua diferenciação do "vagabundo".

A referência da instituição para esses adolescentes pode ser entendida como um reflexo da lógica do mercado de trabalho. 
Lógica essa em que o que vale é o capital, e a força humana de trabalho só conta enquanto parcela imprescindível para a reprodução desse mesmo capital. A formação profissional aparece como um processo, ou uma relação social, a que estão presentes os mecanismos de regulação produtiva e organizacional, de valorização e normatização do trabalho, o que pode explicar, em parte, a perda gradativa do caráter educacional da formação, pois essa passa a voltar-se às necessidades do mercado. Nesse sentido, foi posto em prática um redimensionamento da educação profissional, historicamente responsabilidade do Ministério da Educação, para o Ministério do Trabalho e Emprego (MTE).

Seguindo essa lógica, o Estado, ao delegar ao SENAC o papel de "formar" esses adolescentes, desresponsabiliza-se pelo processo. E a referência dessa instiuição para os adolescentes passa a representar uma introjeção do sentido do mercado, via sentido da formação, marcada pela confluência do que concebem os empresários (mercado) e o Estado. Reproduzem-se, assim, os valores vigentes em nossa sociedade, ocultando-se as reais condições sociais que regem as vidas desses sujeitos, como chamam atenção Guareshi (1988) e Frigotto (2007). Sobre essa questão, Beisiegel (1988) já havia chamado atenção para o fato de um curso técnico não ser suficiente para se conseguir um emprego, apesar de imaginário contrário já se fazer presente quando da criação do SENAC na década de 1940.

Com o presente estudo, pretendeu-se trabalhar com o adolescente concreto, ou seja, dando um caráter sócio-histórico a esse conceito generalizante. Buscando-se superar a visão da adolescência como fase natural do desenvolvimento, passa-se a considerá-la como fase de desenvolvimento na sociedade moderna ocidental, uma vez que ela não é universal dos seres humanos, é histórica, como afirmam Bock e Liebesny (2007). Essa motivação para participar, expressa pela categoria "inserção no mercado de trabalho", é bastante reveladora da condição de adolescência de classe popular nesse contexto da formação profissional, revelando o que se constitui como questões e problemas para eles e quais os códigos que servem de suporte para enfrentarem os conflitos atravessados em suas vidas, o que também vale para a categoria "necessidade financeira", que será tratada a seguir.

No que diz respeito à motivação para participar, expressa pela categoria "necessidade financeira" tanto para os participantes quanto para os egressos, foi manifestada através do "desejo de ter renda", das "dificuldades financeiras da família", do "desejo de ter independência ou autonomia".

O depoimento de um participante de 17 anos dá conta dessa motivação: "Eu decidi, assim, pelo uma parte porque eu precisava trabalhar e preciso ficar trabalhando, né? Como um modo, assim, de ajudar em casa". Bem como o depoimento deste outro sujeito da mesma idade:"Tava difícil a barra lá em casa. Eu moro só com minha avó e tinha que pagar luz, telefone, essas coisas". Tais depoimentos representam bem o sentido da motivação para participar expresso por meio da categoria necessidade financeira.

Esse anseio por auferir uma renda também foi encontrado por Frigotto (2008) que considera que os jovens se inserem nos múltiplos espaços de trabalho por necessidade. De uma forma ou de outra, buscam gerar condições de sobrevivência.
Nesse aspecto, há uma conexão entre trabalho na condição de aprendizagem e consumo, sendo que a formação para o trabalho adquire sentido para os adolescentes pelo fato de ser encarada como via de acesso social e possibilidade de aquisição de certos bens de consumo.

Outros estudos (Cervini \& Burger, 1991; Dauster, 1992; Madeira \& Bercovich, 1992) também chamam atenção para a busca de emprego associada ao desejo de conquista de autonomia, liberdade e de consumo de bens que os pais não podem proporcionar em virtude da situação de pobreza em que vivem.

A categoria "desejo de aprendizado" foi a de menor frequência das três primeiras categorias relacionadas à motivação para participar do programa. Tanto os participantes quanto os egressos esperavam adquirir conhecimento teórico e prático em relação ao trabalho, seja no que se refere ao mercado de trabalho, seja à prática que este viria a desenvolver na empresa.

O fato de a "necessidade financeira" se configurar como uma das principais temáticas enunciadoras da motivação dos adolescentes para participar do programa e a "aprendizagem" ficar em terceiro plano pode demonstrar o sentido que as políticas de formação profissional vêm assumindo no contexto brasileiro. Como sinalizam alguns estudos (Frigotto, 2007; Neves, 2006; Sposito \& Carronchano, 2005), há um processo de secundarização ou, em alguns casos, da negação de sua base educativa.

Nesse sentido, as políticas sociais de formação incidem sobre as necessidades imediatas de sobrevivência, reproduzindo, assim, uma prática assistencialista, com pouca ação no sentido de mudança efetiva das condições de vida, principalmente, em termos de protagonismo juvenil, conforme assinalam Guareshi (1988), Sposito e Carronchano (2005), Neves (2006) e Frigotto (2007).

$\mathrm{Na}$ medida em que o discurso da inserção e o caráter assistencialista se sobrepõem ao caráter formador, caminha-se em moldes semelhantes à perspectiva do trabalho como antídoto à marginalidade, uma vez que ocupa as "classes perigosas", mantendo esses adolescentes num contexto de vigilância e disciplinamento. E sem proporcionar melhoria nas condições socioeconômicas desses jovens, porque o mercado não absorverá todos, haja vista a configuração que esse vem assumindo diante do aumento de competitividade de uma economia globalizada, das inovações tecnológicas e das novas formas de organização de produção, que exige trabalhadores superqualificados.

Por meio das entrevistas coletivas, procurou-se, também, conhecer qual das três principais motivações anunciadas pelos adolescentes - "possibilidade de inserção no mercado de trabalho", "necessidade financeira" e "desejo de aprendizado", teve maior influência na decisão deles em participar do programa.

O depoimento de uma adolescente de 16 anos demonstra bem como essa questão era percebida: "Financeiro com certeza, quem disser que não foi isso, pode ter certeza que está mentindo. Pode ter certeza que a questão financeira pesa mais, é o que mais motiva".

Portanto, nas entrevistas coletivas as falas denotaram que o sentido dessa formação, tanto para os participantes quanto para os egressos, teve como a principal temática enunciadora da 
motivação a "necessidade financeira", seguida da "possibilidade de inserção no mercado de trabalho" e, por último, da questão do "desejo de aprendizado".

Ora, segundo o ponto de vista dos autores, inserção e aprendizado é que deveriam ser a grande contribuição do programa, mas que, principalmente no tocante ao aprendizado, ficam em terceiro plano na percepção dos adolescentes, "distorção" essa que pode estar associada ao quadro de injustiça social que se faz presente na sociedade brasileira, bem como a ausência de crescimento, desarticulação e desestruturação do mercado de trabalho nacional. Tal programa parece cumprir mais o papel de distribuição de renda, constituindo-se como uma política que apenas ataca os efeitos da exclusão. E essa ênfase no assistencialismo e transferência de renda, como coloca Frigotto (2007) e Sposito e Carronchano (2005), constituem-se uma tábua de salvação para os que correm risco de desemprego ou para os desempregados, ou seja, "alívio da pobreza".

Ter a questão financeira como o sentido é manter o controle, fazer a regulação de quem tem acesso ao mercado, principalmente pelo tipo de formação baseada no modelo de competência. Sendo competências entendida como um saber que permite ao sujeito adequar-se a tarefas e situações, apelando para noções, conhecimentos, informações, procedimentos, métodos, técnicas ou ainda a outras competências mais específicas (Perrenoud, 1999). Nesse sentido, recorrendo-se a uma terminologia foucaultiana, pode-se considerar que há disciplinamento e controle social, conforme discussão que segue acerca do que esses adolescentes aprenderam.

\section{Sentido do aprendizado}

Quando os adolescentes se referiram ao que aprenderam, ao longo da experiência no curso teórico, nas falas, tanto dos participantes quanto dos egressos, destacaram-se as categorias "disciplinamento" e "conteúdo do curso teórico".

O "disciplinamento" se fez presente na totalidade das falas dos adolescentes e denotava que eles tinham aprendido a saber respeitar, ser paciente, lidar com pessoas e moldar-se às normas da empresa, bem como desenvolver o gosto pelo trabalho.

O depoimentos abaixo, de uma adolescente de 17 anos, dá conta dessa "pedagogia ortopédica" (Foucault, 1997) no contexto desse programa de aprendizagem: “(...) mesmo aqueles mais desinteressados, no final, eles tornam-se interessados, porque têm que ter responsabilidade... A responsabilidade de o que mandarem você fazer, ter que fazer direito, não pode errar".

No momento em que os adolescentes trataram do que aprenderam no "conteúdo do curso teórico", fizeram referência a conteúdos de: disciplinas básicas, como português, matemática e informática; disciplinas interpessoais, como saúde e segurança no trabalho, relações humanas, direito e ética; e específica que se tratava de uma disciplina de administração.

A análise documental dos dados empíricos revelou que ética, no programa, não se configurava como ciência da moralidade, mas, sim, como mecanismo disciplinador, uma vez que, em um módulo visto no curso teórico, eram apresentadas as expectativas, por parte dos gestores do programa, acerca de como esses adolescentes deveriam comportar-se na empresa. $\mathrm{O}$ que pode ter sido constatado, também, a partir das falas dos sujeitos participantes do estudo. A fala desta jovem de 19 anos é elucidativa desse aspecto: "Ética era tipo como você deve se comportar, em relação à aparência, em relação ao dever no trabalho, no curso. É isso (risos), coisas do dia a dia".

Quando os adolescentes se referiram ao que faziam, na parte prática do programa, as falas deram conta das categorias "serviços administrativos", "serviços de apoio" e "serviço comercial".

A categoria "serviços administrativos" demonstra que eles desenvolviam atividades de office boy, de arquivador, realização de cadastro e de operação de máquina fotocopiadora. A categoria "serviços de apoio" evidencia que esses adolescentes serviam cafezinho e água, faziam controle de limpeza e da organização de prateleiras e embalavam compras. Os "serviços comerciais" apareceram apenas com os egressos, o que evidencia que alguns adolescentes também atuavam como vendedores nas empresas.

Diante dessas atividades, que não se caracterizam como trabalho educativo, como reza a Consolidação das Leis Trabalhistas (CLT), ECA e a própria cartilha de aprendizagem, buscou-se verificar se os adolescentes consideraram tais práticas adequadas, tanta para idade quanto para uma atividade de aprendizagem.

E apesar de os dados revelarem claramente que as atividades realizadas diferem do que determinam aspectos legais e a cartilha de aprendizagem, tanto no que se refere à compatibilidade com o desenvolvimento do adolescente, quanto a uma articulação entre a parte teórica e prática do programa. Os adolescentes consideraram que a parte prática desenvolvida em tal proposta de formação profissional estava adequada, apesar de não conseguirem dar uma justificativa plausível para tal. Esse aspecto pode ser verificado na fala de um jovem de 18 anos: "Era compatível, algumas coisas da parte administrativa era compatível. O porquê eu não sei explicar, mas sei lá (...) quando eu fui digitar uns negócio lá que me pediram, o professor tinha ensinado (a usar o programa Word para digitar)".

Deparamos-nos, assim, com um paradoxo, pois a avaliação dos adolescentes deu-se no sentido de considerar a prática como sendo adequada, apesar de falas que deixaram clara a incompatibilidade, o que pode ser observado no depoimento desta adolescente: "Lá, normalmente, eles exigem muito de você. Lá era igual a um emprego (...) eles me abordavam assim como se eu fosse uma funcionária qualquer da empresa (...) eu acho que foi muito cansativo, porque eles exigiam bastante". Bem como na fala de um dos sujeitos de 17 anos, que evidencia envolvimento de alguns adolescentes em atividades insalubres: "Às vezes eu ia ajudar os meninos, pra separar a carga de roupa pesadas (vestimentas ou lençóis provenientes das salas cirúrgicas) na lavanderia (de um hospital) eu aprendi que era um risco muito grande da pessoa perder um braço".

Os dados empíricos, a partir dessas avaliações, demonstram que os sujeitos participantes do estudo não têm clareza de que o trabalho educativo se caracteriza como uma atividade de caráter pedagógico, com o intuito de se desenvolver as habilidades desses adolescentes, conforme determina a Lei de Aprendizagem.

Questiona-se, assim, que subjetividade emerge entre esses sujeitos em formação, cujas experiências de vida vinham particularmente da formação profissional, propiciadoras da 
aquisição de conhecimentos de caráter manual em detrimento de um conhecimento de caráter mais intelectual.

E o que significa essa realidade diante das novas configurações do mundo do trabalho, em que as empresas recorrem cada vez mais às inovações tecnológicas? O que esses adolescentes terão a oferecer para o mercado de trabalho cada vez mais exigente? Se a escola e as propostas de formação e qualificação dos trabalhadores precisam ajustar-se a essa nova realidade globalizada e competitiva que demanda uma produção mais enxuta e automatizada, qual demanda o profissional formado em Serviços Administrativos vai atender?

\section{Sentido da contribuição da experiência}

Quando questionados acerca de como a formação profissional que receberam poderia ajudá-los a se inserir no mercado de trabalho, as respostas, tanto dos participantes quanto dos egressos, dão conta das categorias: "disciplinamento", "vivência de uma experiência", "carteira assinada", "referência" e "aprendizado". Para ambos os grupos de adolescentes, houve o predomínio do "disciplinamento" e "vivência de uma experiência".

As falas dos adolescentes demonstram a avaliação de que suas oportunidades de inserção no mercado de trabalho se ampliam pelo fato de terem passado por esse processo de disciplinamento, bem como pela experiência que os mesmos adquiriram ao longo da parte prática do programa e pelos referenciais que eles podem apresentar, seja em relação ao fato de terem "estagiado" numa empresa renomada, seja pelo fato de terem feito um curso no SENAC.

Nesse sentido, o disciplinamento é compreendido como instrumentalização necessária para se inserir profissionalmente, talvez porque o SENAC seja reconhecido pelo mercado de trabalho como capacitado a formar e qualificar trabalhadores. $\mathrm{E}$, uma vez que o que os adolescentes almejam a aquisição da identidade de trabalhador, dispõem-se a se submeterem a esse processo de disciplinarização.

Frigotto (2007) ajuda-nos a compreender essa ênfase no disciplinamento por parte desse programa de qualificação profissional, quando considera que, com a contração do mercado de trabalho, fruto das inovações do mundo contemporâneo, houve um aumento da subsunção do sistema educacional (e especialmente da educação profissional) aos requisitos do capital, uma vez que há, "nessas políticas, uma perspectiva estrita de adaptação aos objetivos do mercado e não aos direitos sociais dos trabalhadores e objetivos sociais mais amplos" (p. 1130).

Esse processo de subordinação, no campo da educação e formação, efetiva-se mediante a delimitação dos conteúdos e da gestão dos processos educativos. Nesse contexto, o disciplinamento ganha relevo, uma vez que faz com que os futuros trabalhadores coloquem seu potencial comportamental à disposição e a serviço da produtividade da empresa.

Nesse sentido, o SENAC configura-se como um micropoder, uma vez que detém um saber e produz o real, por meio de uma transformação técnica dos indivíduos. Foucault (1982) caracteriza essa transformação como sendo uma relação de poder, o que, em nossa sociedade, recebe o nome de normalização. $\mathrm{Na}$ visão desse teórico, esse poder constitui, produz, cria identidades e subjetividades, uma vez que, por meio dessa relação, emergem corpos submissos e exercitados, corpos "dóceis". Aumentamse as forças do corpo, em termos econômicos de utilidade, e diminuem-se essas mesmas forças, em termos políticos, de obediência, através do disciplinamento.

Foucault (1988), para explicar a dinâmica de uma sociedade disciplinar, faz referência a um biopoder, tal teórico considera que enquanto a disciplina age sobre os indivíduos, o biopoder age sobre a espécie, "no corpo-espécie, no corpo transpassado pela mecânica do ser vivo e como suporte dos processos biológicos" (1988, p. 152). Pode-se entender, então, o biopoder como uma gestão da vida como um todo, técnicas de poder sobre o biológico, com o propósito de modificá-lo, transformálo, aperfeiçoá-lo e produzir conhecimento, saber sobre ele, para melhor manejá-lo.

Dessa forma o biopoder trata de gerir a vida em toda a sua extensão, de organizá-la, vigiá-la, para que possa ser incluída, de forma controlada, nos aparelhos de produção capitalistas.

Portanto, a formação para o trabalho aparece como um princípio de ordem e regularidade. Numa leitura foucaultiana, a utilidade dessa proposta de formação está na constituição de um esquema de submissão individual e de seu ajustamento a um aparelho de produção.

Logo, o sentido da formação profissional, no que se refere à inserção no mercado, coloca em terceiro plano o conteúdo transmitido no curso, salientando o disciplinamento e a experiência como elementos de maior importância para os ajudarem a conseguir um emprego, ou seja, os adolescentes passam por um processo de disciplinamento, e a aprendizagem advinda dessa vivência parece não ter grandes contribuições, o que denota que essa "nova" proposta de formação não se diferencia tanto do que historicamente tem sido destinado a crianças, adolescentes e jovens de classes populares, tanto pelo Estado quanto pelo SENAC.

\section{Considerações finais}

Com base nas categorias representativas dos núcleos de sentido que emergiram das falas dos sujeitos, percebe-se que: o que o mercado requer e o Programa oferece passa pelas dimensões de uma prática comprovada, e não pelo aprendizado; o programa é visto como via de acesso social ao mercado e possibilidade de aquisição de certos bens; a base educativa dessa proposta de formação profissional não assume papel de destaque na ótica dos adolescentes, e tais políticas parecem assumir mais um papel de distribuição de renda; e a inserção no mercado de trabalho é encarada como mais ampla pelos adolescentes, pelo fato de terem passado por um processo de disciplinamento, seja em relação ao fato de terem "estagiado" numa empresa renomada, seja pelo fato de terem feito um curso no SENAC.

Reproduz-se, dessa forma, o modelo da escola, enfatizandose mais o seu caráter disciplinador, não se configurando como uma política de direitos, mas de contenção dos pobres, uma vez que assume um papel de agente educativo, relevante não só no resgate e "reforço" de conteúdos escolares, mas, também, por possibilitar uma educação para o trabalho, pelo qual os alunos recebem um conjunto de informações relevantes para o 
domínio de determinado ofício, embora não haja aprofundamento que possibilite condições para prosseguirem seus estudos ou qualificarem-se em outros domínios, inclusive no processo prático durante o curso que estimula ao aprendiz a realização de trabalhos não condizentes com os objetivos do SENAC. Esse processo acaba por comprometer, em alguns aspectos, a proposta de aprendizagem, sendo esses adolescentes disciplinados, uma vez que demonstram satisfação pelo fato de estarem envolvidos em um "trabalho" remunerado, o que lhes permitem não só complementarem a renda familiar como comprar seus próprios objetos pessoais.

Nesse sentido, essa política social parece ser desenvolvida justamente de modo a promover o assistencialismo, de forma que a efetivação de um direito pode acabar comprometendo a construção de raciocínio crítico da sua situação, pois esses adolescentes disciplinados demonstram submissão a um poder hierárquico, a cobranças, pressões e responsabilidades e a conformar-se com trabalhos manuais que pouco exigem em termos cognitivos, pois essa é uma das condições para que tenham direito a essa "renda extra".

Isso faz com que essa nova proposta de formação profissional em pouco se diferencie das políticas de formação para o trabalho, outrora formuladas para crianças e jovens das classes populares, pois, como visto com as Rodas de expostos nas Misericórdias, os Asilos da Infância dos Menores Desvalidos, as Escolas de Aprendizes Artífices e o Programa Bom Menino, historicamente sempre se fez presente uma concepção excludente, exploratória e voltada para o disciplinamento.

A grande novidade desse programa parece consistir apenas no discurso, uma vez que ele apresenta, em sua elaboração teórica, preocupações acerca do desenvolvimento físico, psíquico, moral e social dos adolescentes, ou seja, um Biopoder.

\section{Referências}

Amparo, D. M., Galvão, A. C. T., Cardenas, C., \& Koller, S. H. (2008). A escola e as perspectivas educacionais de jovens em situação de risco. Psicologia Escolar e Educacional, 12, 69-88.

Bardin, L. (1995). Análise de Conteúdo. (L. A. Reto, \& A. Pinheiro, Trads.). São Paulo: Edições 70/Martins Fontes. (Obra original publicada em 1977)

Bock, A. M. B., \& Liebesny (2007). Adolescência como construção social: estudo sobre livros destinados a pais e educadores. Psicologia Escolar e Educacional, 11, 63-76.

Beisiegel, C. R. (1988). Política educacional e programas de alfabetização. Idéias, 1, 16-22.

Brasil (1988). Constituição da Republica Federativa do Brasil. Brasília/DF: Autor.

Brasil (1990). Estatuto da Criança e Adolescente, Lei 8.069, de 13 de julho de 1990. Brasília/DF: Autor.

Brasil (2000). Lei da Aprendizagem, Lei n. 10.097, de 19 de dezembro de 2000. Brasília/DF: Autor.

Cassab, M. A. T. (2005). Jovens e oportunidades: a desnaturalização da cidade desigual. Revista Serviço Social e Sociedade, 26, 49-62.

Centro Internacional de Investigação e Documentação sobre Formação Profissional-CINTERFOR (1998). Formación y Trabajo. Rio de Janeiro: Senai/DN.

Cervini, R., \& Burger, F. (1991). O menino trabalhador no Brasil. In A. Fausto \& R. Cervini (Orgs.), O trabalho e a rua: crianças e adolescentes no Brasil urbano dos anos 80 (pp.17-46). São Paulo: Cortez.

Coimbra, C. M. B., \& Nascimento, M. L. (2005). Ser jovem, ser pobre é ser perigoso? Recuperado de http://www.slab.uff/exibetexto2. php?link $=. \% 2$ Ftexto23.htm\&codtexto $=23 \& \mathrm{cod}+23 \& \mathrm{tp}+\mathrm{t} \&$ nome_autor

Cristo, K. K. V., \& Rangel, P. C. (2007). Os direitos da criança e do adolescente, a lei de aprendizagem e o terceiro setor. Recuperado de www.mpes. gov.br/.../17_2086109351772008_OS\%20DIREITOS\%20DA\%20 CRIANÇA\%20E\%20DO\%20ADO

Cruz, L., Hillesheim, B., \& Guareschi, N. (2005). Infância e políticas públicas: um olhar sobre as práticas psi. Psicologia \& Sociedade, 17, 42-49.

Dauster, T. (1992). Uma infância de curta duração: trabalho e escola. Cadernos de Pesquisa, 82, 31-36.

Foucault, M. (1982). Microfísica do poder. Rio de Janeiro: Graal.

Foucault, M. (1988). História da Sexualidade: a vontade de saber. Rio de Janeiro: Graal.

Foucault, M (1997). Vigiar e Punir. Petrópolis: Vozes.

Frigotto, G. (2007). A relação da educação profissional e tecnológica com a universalização da educação básica. Educação e Sociedade, 28, 1129-1152.

Frigotto, G. (2008). Educação profissional e capitalismo dependente: o enigma da falta e sobra de profissionais qualificados. Trabalho, Educação e Saúde, 3, 521-536.

Gonçalves, H. S., \& Garcia, J. (2007). Juventude e sistema de direitos no Brasil. Psicologia: Ciência e Profissão, 27, 538-553.

Guareshi, P. A. (1988). O "programa bom menino" ou de como preparar mão-deobra barata para o capital. Revista Serviço Social e Sociedade, 27, 127-138.

Kuhlmann Jr., M. (2005). Uma história da infância: da idade média à época contemporânea no ocidente. Caderno de Pesquisa. 35, 239-242.

Madeira, F., \& Bercovich, A. (1992). A “onda jovem” e seu impacto na população economicamente ativa de São Paulo. Planejamento e políticas públicas, $8,34-56$

Marcílio, M. L. (1999). A roda dos expostos e a criança abandonada na história do Brasil. In M. C. Freitas (Org.), História social da infância no Brasil (pp. 51-76). São Paulo: Cortez.

Martins, C. F., \& Brito, L. M. T. (2003). A inserção do psicólogo no sistema de atendimento ao adolescente em conflito com a lei no Brasil. In A. M. JacóVilela, A. C. Cerezzo \& H. B. C. Rodrigues (Orgs.), Clio-Psyché paradigmas: historiografia, psicologia, subjetividades (pp. 371-377). Rio de Janeiro: Relume Dumará; FAPERJ.

Neves, D. P. (2006). Juventude, trabalho e instituições filantrópicas. Saúde e Sociedade, 15, 99-114.

Perrenoud, P. (1999). Construir competências é viras as costas aos saberes? Pátio. Revista pedagógica, 11, 15-19.

Pilotti, F., \& Rizzini, I. (1995). A arte de governar crianças: a história das políticas sociais, da legislação e da assistência à infância no Brasil. Rio de Janeiro: Universidade Santa Úrsula.

Rocha, T. (2007). O contrato de aprendizagem e sua contribuição na redução da criminalidade do menor. (Monografia não publicada). Centro Universitário Eurípides de Marília, Fundação de Ensino Eurípides Soares da Rocha, Marília-SP.

Serviço Nacional de Aprendizagem Comercial - SENAC (2004). Projeto Adolescente Aprendiz: o futuro começa aqui. Paraíba: SENAC.

Siqueira, A. C., \& Dell'Aglio, D. D. (2006). O impacto da institucionalização na infância e na adolescência: uma revisão de literatura. Psicologia \& Sociedade, 18, 71-80.

Sposito, M. P., \& Corrochano, M. C. (2005). A face oculta da transferência de renda para jovens no Brasil. Tempo social, 7, 141-172.

Trevisan, A. P., \& Bellem, H. M. (2008). Avaliação de políticas públicas: uma revisão teórica de um campo em construção. Revista de Administração Pública, 42, 529-50. 

de fevereiro de 2006, agregou-se um ano a mais nesta etapa da escolarização.

Orlando Júnior Viana Macêdo, mestre em Psicologia Social pela Universidade Federal da Paraíba, é doutorando em Psicologia Social pela Universidade Federal da Paraíba e membro do Núcleo de Pesquisas e Estudos sobre o Desenvolvimento da Infância e Adolescência. Endereço para correspondência: Rua Tenente Antônio Sales, 230, Bairro Novo Juazeiro - Juazeiro do Norte - CE, Brasil. CEP63030-390. Telefone: (88) 8807-0618. Email: orlandojrvm@yahoo.com.br

Maria de Fátima Pereira Alberto, doutora em Sociologia pela Universidade Federal de Pernambuco, é professora Associada do Departamento de Psicologia e do Programa de Pós-Graduação em Psicologia Social da Universidade Federal da Paraíba, coordenadora do Núcleo de Pesquisas e Estudos sobre o Desenvolvimento da Infância e Adolescência, e pesquisadora do CNPq. Endereço: Ambiente 25, Centro de Ciências Humanas, Letras e Artes, Universidade Federal da Paraíba. Cidade Universitária - Campus I - João Pessoa/PB, Brasil. CEP 58059-900. Telefone: (83) 3216-7581, (83) 8821 2390. Email: jfalberto@uol.com.br 